\title{
Paratesticular Tumors in the Service of Urology Ibn Rochd UHC: Epidemioclinical and Therapeutic Aspects
}

\author{
W. Bai, M. Graiouid, G. Hatim, A. Doumer, M. Dakir, A. Debbagh, R. Aboutaieb
}

\section{ABSTRACT}

Objective: To analyze the frequency, clinical and therapeutic aspects of paratesticular tumors in the urology department of the Ibn Rochd UHC.

Patients and methods: Retrospective study of 5 patients with partesticular tumors treated in the urology department of Ibn Rochd UHC between January 2014 and December 2019. The parameters studied were age, circumstances of discovery, histological type of the tumor and the treatment performed.

Results: Five paratesticular tumors were recorded among all patients admitted for a tumor of the urogenital system, representing a prevalence of $0.52 \%$. The mean age of onset was 27 years (range 17-65 years). The circumstances of discovery were a scrotal mass in $60 \%$ of the cases, that is to say three patients and an inguinoscrotal mass in two patients. Several histological types of tumors have been recorded: three cases of rhabdomyosarcomas, either $60 \%$, one case of sarcoma, either $20 \%$, and one case of fibroma. The modalities of the surgical treatment carried out were enlarged orchidectomy by upper inguinal approach with lymph node dissection in two patients, enlarged orchidectomy by upper inguinal approach without lymph node dissection in two cases and one case of tumerectomy.

Conclusion: Paratesticular tumors are rare. They are found mainly in young adults. The clinical presentation is variable and the diagnosis often late. Management is multidisciplinary but remains essentially surgical. Our study illustrates the great histopathological variability of paratesticular tumors.

Keywords: scrotal mass; tumor; Paratesticular.
Published Online: October 30, 2020

ISSN: 2593-8339

DOI: $10.24018 /$ ejmed.2020.2.5.147

\section{W. Bai}

Departement of Urology, UHC Ibn Rochd, Casablanca,Morocco.

M. Graiouid*

Departement of Urology, UHC Ibn Rochd, Casablanca,Morocco.

(e-mail: graiouidmehdi@gmail.com)

G. Hatim

Departement of Urology, UHC Ibn Rochd, Casablanca,Morocco.

A. Doumer

Departement of Urology, UHC Ibn Rochd, Casablanca,Morocco.

M. Dakir

Departement of Urology, UHC Ibn Rochd, Casablanca,Morocco.

A. Debbagh

Departement of Urology, UHC Ibn

Rochd, Casablanca,Morocco.

R. Aboutaieb

*Corresponding Author

\section{INTRODUCTION}

Paratesticular tumors are a term used to describe tumors occurring in the scrotum but not of testicular origin and include the epididymis, spermatic cord, vaginal membrane and various support structures [1]. These are rare tumors. Surgical resection is essential and is normally performed by radical orchidectomy with high dissection of the spermatic cord using an inguinal approach [2]. The aim of this study is to highlight the epidemioclinical and therapeutic aspects of paratesticular tumors seen in the urology department of Ibn Rochd UHC.

\section{PATIENTS AND METHODS}

A retrospective study of paratesticular tumors treated in the urology department of Ibn Rochd UHC between January 2014 and December 2019. Five patients were treated for paratesticular tumors in all patients registered for a tumor of the urogenital system. The parameters studied were age, circumstances of discovery, histological type of tumor and the treatment performed. Patient information was obtained from the department's registers and patient records.

\section{RESULTS}

A total of 5 patients diagnosed with a paratesticular tumor were admitted during the study period to all urogenital tumors registered in the department, either a prevalence of $0.52 \%$. The average age was 27 years with extremes ranging from 17 at 65 years of age; the diagnostic circumstances were the discovery of a scrotal mass in $60 \%$ of the patients, and an inguino-scrotal mass in $40 \%$ of the cases. The modalities of the surgical treatment carried out were enlarged orchidectomy by inguinal approach with lymph node dissection in $40 \%$ patients, enlarged orchidectomy by inguinal approach without lymph node dissection in two cases and one case of tumerectomy. Several histological types of tumors have been recorded: the most frequent was rhabdomyosarcomas with $60 \%$, one case of sarcoma, either 
$20 \%$, and one case of fibroma. Table 1 summarizes the observation of our patients.

TABLE 1: SUMMARY OF PATIENT OBSERVATIONS

\begin{tabular}{|c|c|c|c|c|}
\hline Patient & Age & Clinical & Treatment & Histology \\
\hline 1 & 17 & $\begin{array}{l}\text { Scrotal } \\
\text { mass }\end{array}$ & $\begin{array}{c}\text { Enlarged } \\
\text { orchidectomy } \\
\text { with lymph } \\
\text { node dissection }\end{array}$ & Rhabdomyosarcoma \\
\hline 2 & 19 & $\begin{array}{c}\text { Masse } \\
\text { scrotale }\end{array}$ & $\begin{array}{l}\text { Enlarged } \\
\text { orchidectomy } \\
\text { with lymph } \\
\text { node dissection }\end{array}$ & Rhabdomyosarcoma \\
\hline 3 & 17 & $\begin{array}{l}\text { Inguino- } \\
\text { scrotal } \\
\text { mass }\end{array}$ & $\begin{array}{c}\text { Enlarged } \\
\text { orchidectomy }\end{array}$ & Rhabdomyosarcoma \\
\hline 4 & 20 & $\begin{array}{l}\text { Inguino- } \\
\text { scrotal } \\
\text { mass }\end{array}$ & Tumerectomy & Ewing sarcoma \\
\hline 5 & 65 & $\begin{array}{l}\text { Scrotal } \\
\text { mass }\end{array}$ & $\begin{array}{c}\text { Enlarged } \\
\text { orchidectomy } \\
\text { without lymph } \\
\text { node dissection }\end{array}$ & Fibroma \\
\hline
\end{tabular}

\section{DISCUSSION}

Paratesticular tumor is a term used to describe tumors occurring in the scrotum but not of testicular origin and includes the epididymis, the spermatic cord, the vaginal and various support structures [3]. Thus, tumors of mesenchymal, epithelial and mesothelial origin can, however, develop in this set of structures. Those are rare tumors, which represent less than $5 \%$ of all testicular masses [4]. The majority of all paratesticular masses is benign and includes lipomas, adenomatoid tumors and leiomyomas, however less than a third are malignant with $90 \%$ of them being sarcomas [5]. The majority of paratesticular sarcomas originate from the spermatic cord [6]. Men in their sixth decade have the highest incidence of paratesticular sarcomas [7]. Rhabdomyosarcomas tend to affect men during the first two decades of their lives with the presence of an aggressive subtype [6]. In our study the prevalence was $0.52 \%$ with an average age of 27 years and extremes ranging from 17 to 65 years. Symptoms are poor and insidious leading to a late diagnosis [8]. A scrotal mass (85\%) was the most common presentation, followed by trauma or bruising $(8 \%)$, hydrocele and hernia (6\%) [9]. During physical examination, a mass is usually palpable, however; in $15 \%$ to $20 \%$ of cases, the tumor can be associated with the hydrocele, which limits testicular examination [10]. Ultrasound of the scrotum and its contents can make a reliable difference between a testicular and a paratesticular mass with a sensitivity reported as> 95\% [11]. It is characterized by its availability, absence of radiation exposure and the ability to determine the location and consistency of the scrotal masses, this is the first radiological examination requested. MRI is efficient, using surface antennas; the tumor appears homogeneous, in T1 and of heterogeneous appearance, in $\mathrm{T} 2$ with signal intensity similar to the normal testicle. Because of the albugineal hyposignal, in $\mathrm{T} 2$, the mass is clearly separated from the testicle. There are no tumor markers that can help with the diagnosis, which is based solely on histological examination of the orchidectomy part [12]. The scanner can be used for the evaluation of retroperitoneum and current comments are that all patients undergo a thin cut $(5 \mathrm{~mm}$ for 10 years, $7 \mathrm{~mm}$ for 4 to 10 years) abdominal or pelvic scanner with double contrast to identify the affected areas and retroperitoneal lymph nodes for staging. Regional lymph nodes include the iliac and retroperitoneal nodes up to the hilum of the homolateral kidney. Studies have shown that $65 \%$ to $94 \%$ of the affected retroperitoneal lymph nodes are observed on imaging [13]. Surgical treatment remains difficult. Ignorance of the type of tumor preoperatively should lead to systematically approaching the tumor by the inguinal route, with primary control of the cord to the inguinal orifice associated with a histopathological study in extemporaneous. When the benignity of the lesion is confirmed, excision of the tumor and the vaginal is the treatment of choice. If the benign nature is impossible to determine extemporaneously, an enlarged orchidectomy taking away the epididymotesticular block and the entire spermatic cord up to the deep inguinal orifice is often performed [14]. This surgical treatment is combined with chemotherapy and radiotherapy cures in the event of a malignant tumor. The most widely used chemotherapy protocol includes the combination of vincristine, actinomycin, cyclophosphamide (VAC) started one month after surgery. Adjuvant radiation therapy has a more solid evidence base for its use, although no consensus on its regular use has been reached. Radiation therapy for sarcomas of the extremities is well documented to obtain an advantage of local control, with a systematic review of its post-surgery adjuvant use citing 90\% local control [14].

\section{CONCLUSION}

Paratesticular tumors are a rare occurrence, found mostly in children and young adults. They require an early diagnosis and a thoraco-abdomino-pelvic extension assessment. The introduction of multi-agent chemotherapy for the treatment associated with surgery has changed the prognosis of the disease.

\section{REFERENCES}

[1] Woodward PJ, Schwab CM, Sesterhenn IA. Extratesticular scrotal masses: radiologic-pathologic correlation. Radiographics 2003; 23:215-240.

[2] Dall'Igna P, Bisogno G, Ferrari A, et al. Primary transscrotal excision for paratesticular rhabdomyosarcoma. Is hemiscrotectomy really mandatory? Cancer.2003; 97:1981-1984.

[3] Unlü Y, Huq GE, Ozyalvaçli G, et al. Paratesticular sarcomas: a report of seven cases. Oncol Lett 2015; 9: 308-312.

[4] Alfarelos J, Gomes G, Campos F, et al. Paratesticular leiomyosarcoma: a case report and review of the literature. Urol Case Rep 2017; 11: 30-32.

[5] Matias M, Carvalho M, Xavier L, et al. Paratesticular sarcomas: two cases with different evolutions. BMJ Case Rep 2014. pii: bcr2014205808.

[6] Matias M, Carvalho M, Xavier L, et al. Paratesticular sarcomas: two cases with different evolutions. BMJ Case Rep 2014. pii: bcr2014205808.

[7] Mechri M, Ghozzi S, Khiari R, et al. A rare cause of a scrotal mass: primary leiomyosarcoma of epididymis. BMJ Case Rep 2009. pii: bcr06.2008.0292.

[8] A. Rakototiana*, F. Hunald, M. Rakotovao, et al. Paratesticular tumors seen in UTH Ravoahangy-Andrianavalona: Epidemioclinical and therapeutical aspects. Progrès en urologie (2009) 19, 632-635. 
[9] Metcalfe PD,Farviar-MohseniH,FarhatW,etal.Pediatrictesticular tumors: contemporary incidence and efficacy of testicular preserving surgery. JUrol2003; 170:2412-5.

[10] Kramer SA. Pediatricurologiconcology. UrolClinNorthAm1985; $12: 31-42$.

[11] Frates MC, Benson CB, DiSalvo DN, et al. Solid extratesticular masses evaluated with sonography: pathologic correlation. Radiology 1997; 204: 43-46.

[12] Mason BJ, Kier R. Sonographic and MR imaging appearances of paratesticular rhabdomyosarcoma. AJR Am J Roentgenol. 1998 Aug; 171(2):523-4

[13] Wiener ES,LawrenceW,HaysD,LobeTE,AndrassyR,Donaldson S, CristW, NewtonW, JohnsonJ, GehanE,etal.Retroperitoneal node biopsy in paratesticular rhabdomyosarcoma. JPediatrSurg 1994; 29:171-7.

[14] Strander H, Turesson I and Cavallin-Ståhl E. A systematic overview of radiation therapy effects in soft tissue sarcomas. Acta Oncol 2003, 42: 516-531 